\title{
APRENDIZADO DA ADESÃO AO MOVIMENTO "O QUE IMPORTA PARA VOCÊ?
}

Autores: Helidea de Oliveira Lima, Angela Zerbielli, Ana Claudia Fernandes ,Deborah Simões, Fernanda Rodrigues, Thamara Petrella.

Instituição: Rede D’Or São Luiz

A empatia é a habilidade humana de compreender os sentimentos e se colocar no lugar do outro. Perceber suas necessidades e compartilhar um elo que pode trazer alento, cuidado, alegria ou até mesmo esperança. E esse é um ponto muito importante no cuidado centrado no paciente. $O$ entendimento da importância desse conceito propiciou o surgimento de campanhas mundiais com o movimento "WMTY (What Matters to You?) - O que importa para você?".

O objetivo deste trabalho é apresentar o aprendizado da adoção do movimento WMTY em 13 unidades numa rede de hospitais privados localizados nos estados de SP, RJ e PE.

Como formalização da adesão ao movimento foi definido que, no dia 06 de junho, data oficial do movimento, as unidades realizariam a abordagem ao paciente - $\mathrm{O}$ que importa para você?". O importante era o colaborador perguntar ao paciente, e após ouvir a resposta em relação ao desejo do paciente, poder atender ao pedido.

Durante o período em que o movimento foi aplicado tivemos muitos aprendizados: Foi um diferencial termos realizado a pergunta "o que importa para você" inicialmente aos próprios colaboradores pois contribuiu para que a equipe entendesse que eles também são importantes para a empresa. Um receio foi comum a todos os funcionários: o que os pacientes poderiam falar? seria possível de atender? Em todas as unidades o sentimento da equipe foi o mesmo. 0 que inicialmente era um receio de pedidos que pudessem ser difíceis de serem atendidos foi substituído por um prazer enorme de atender ao pedido e deixar o paciente feliz!
Aprendemos também que existem várias formas diferentes de abordagem ao paciente. Avaliando os principais apontamentos do paciente foram observadas as seguintes prioridades: presença da família, amigos, carinho, solidariedade e fé; Empatia; comida afetiva; cuidados pessoais de higiene; e visitas de animais de estimação.

A adesão ao movimento teve uma avaliação positiva pelos pacientes com relatos emocionantes citando a importância de serem vistos como uma pessoa (doentes) além da patologia que o trouxe a internação (doença). Os funcionários citaram que a participação no movimento permitiu exercitarem a empatia e tornar mais leve o trabalho diário. A partir daí as unidades entenderam que deveriam usar a campanha na rotina diária, independente da data 06 de junho, inserindo a pergunta no quadro de cuidado a beira leito.

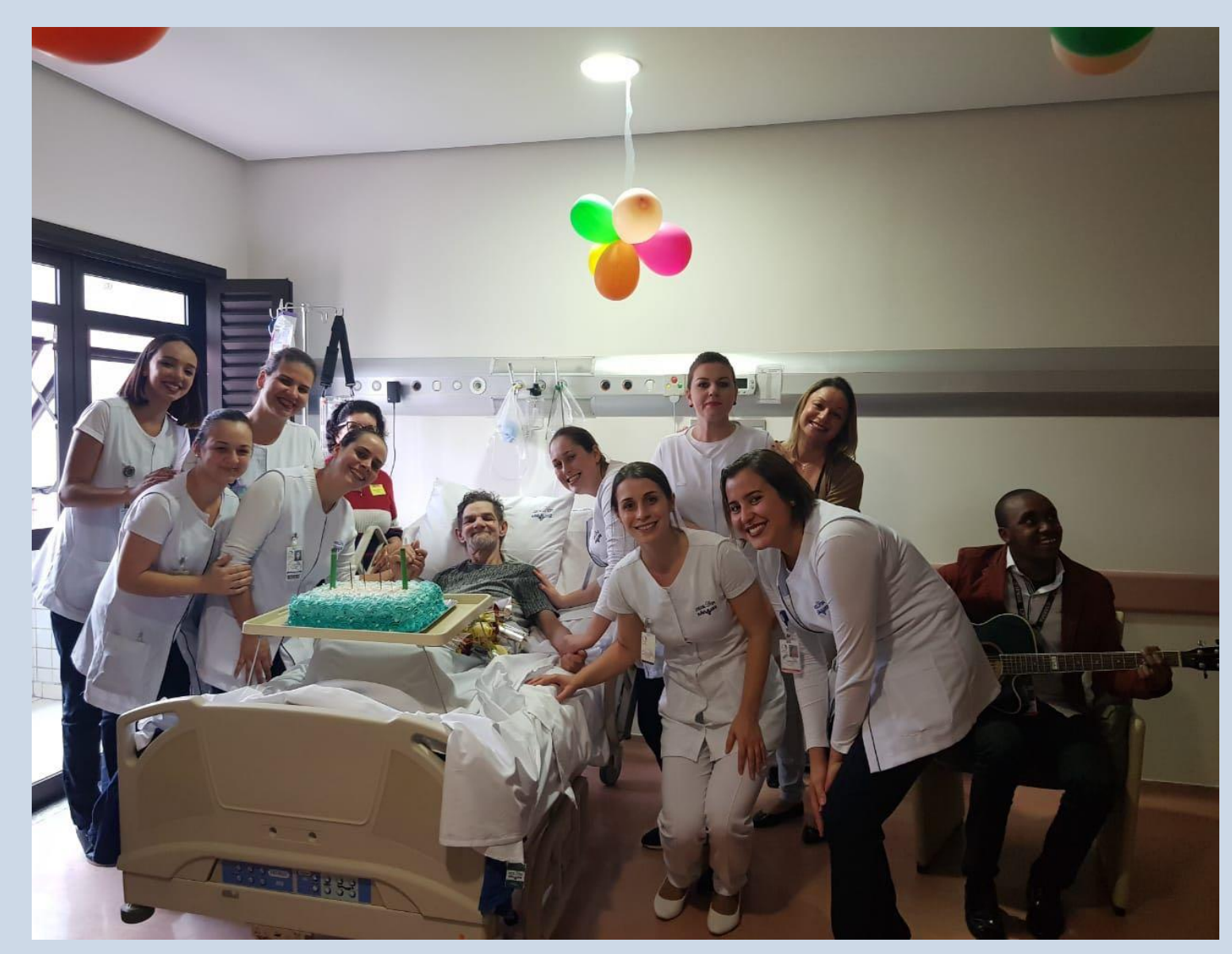

Yu A, Flott K, Chainani N, Fontana G, Darzi A. Patient Safety 2030. London, UK: NIHR Imperial Patient Safety Translational Research Centre, 2016 